\title{
A scoping review of rapid review methods
}

Andrea C. Tricco ${ }^{1,2}$, Jesmin Antony ${ }^{1}$, Wasifa Zarin ${ }^{1}$, Lisa Strifler ${ }^{1,3}$, Marco Ghassemi $^{1}$, John Ivory ${ }^{1}$, Laure Perrier ${ }^{3}$, Brian Hutton ${ }^{4}$, David Moher ${ }^{4}$ and Sharon E. Straus ${ }^{1,5^{*}}$

\begin{abstract}
Background: Rapid reviews are a form of knowledge synthesis in which components of the systematic review process are simplified or omitted to produce information in a timely manner. Although numerous centers are conducting rapid reviews internationally, few studies have examined the methodological characteristics of rapid reviews. We aimed to examine articles, books, and reports that evaluated, compared, used or described rapid reviews or methods through a scoping review.
\end{abstract}

Methods: MEDLINE, EMBASE, the Cochrane Library, internet websites of rapid review producers, and reference lists were searched to identify articles for inclusion. Two reviewers independently screened literature search results and abstracted data from included studies. Descriptive analysis was conducted.

Results: We included 100 articles plus one companion report that were published between 1997 and 2013. The studies were categorized as 84 application papers, seven development papers, six impact papers, and four comparison papers (one was included in two categories). The rapid reviews were conducted between 1 and 12 months, predominantly in Europe (58\%) and North America (20\%). The included studies failed to report $6 \%$ to $73 \%$ of the specific systematic review steps examined. Fifty unique rapid review methods were identified; 16 methods occurred more than once. Streamlined methods that were used in the 82 rapid reviews included limiting the literature search to published literature (24\%) or one database (2\%), limiting inclusion criteria by date (68\%) or language (49 \%), having one person screen and another verify or screen excluded studies (6\%), having one person abstract data and another verify (23\%), not conducting risk of bias/quality appraisal (7\%) or having only one reviewer conduct the quality appraisal (7\%), and presenting results as a narrative summary (78 \%). Four case studies were identified that compared the results of rapid reviews to systematic reviews. Three studies found that the conclusions between rapid reviews and systematic reviews were congruent.

Conclusions: Numerous rapid review approaches were identified and few were used consistently in the literature. Poor quality of reporting was observed. A prospective study comparing the results from rapid reviews to those obtained through systematic reviews is warranted.

Keywords: Systematic review, Rapid review, Scoping review

\section{Background}

Systematic reviews are a useful tool for decision-makers because they can be used to interpret the results of individual studies within the context of the totality of evidence and provide the evidence-base for knowledge translation products, such as patient decision aids, clinical practice guidelines or policy briefs [1]. However, due

\footnotetext{
*Correspondence: sharon.straus@utoronto.ca

'Li Ka Shing Knowledge Institute of St Michael's Hospital, 209 Victoria Street, East Building, Room 716, Toronto, ON M5B 1 W8, Canada

${ }^{5}$ Department of Medicine, Faculty of Medicine, University of Toronto, 27 King's College Circle, Toronto, ON M5S 1A1, Canada

Full list of author information is available at the end of the article
}

to the high level of methodological rigour, systematic reviews take from 0.5 to 2 years to conduct [2] and require considerable skill to execute. According to the Cochrane Collaboration, all procedures including screening citations (titles and abstracts), screening full-text articles, data abstraction, and risk of bias appraisal, should be conducted by two individuals, independently [3]. In addition, technical expertise from librarians, research coordinators, content experts, and statisticians is required.

Health decision-makers (including clinicians, patients, managers, and policy-makers) often need timely access to health information. Although this information can be 
obtained through a systematic review, these research endeavours require enormous resources to complete and the timeframe required to conduct a systematic review may not suit the needs of some decision-makers. For example, it has been estimated that systematic reviews take, on average, 1,139 hours (range 216-2,518 hours) to complete and usually require a budget of at least $\$ 100,000$ [4]. Consequently, decision-makers may be forced to rely on less robust evidence, such as expert opinion or the results of a single small study [5], leading to suboptimal decision-making.

Rapid reviews are a form of knowledge synthesis in which components of the systematic review process are simplified or omitted to produce information in a timely manner [2]. Yet rapid reviews might be susceptible to biased results as a consequence of streamlining the systematic review process [6]. Although numerous rapid review programs exist internationally [7], few studies have examined their methodology. We aimed to examine rapid review approaches, guidance, impact, and comparisons through a scoping review.

\section{Methods}

\section{Definition of a rapid review}

A formal definition for a rapid review does not exist. As such, we used the following working definition, 'a rapid review is a type of knowledge synthesis in which components of the systematic review process are simplified or omitted to produce information in a short period of time' [2].

\section{Protocol}

A scoping review protocol was compiled using guidance from Arksey and O'Malley [8], and revised upon feedback received from the Canadian Institutes of Health Research peer review panel. It is available from the corresponding author upon request.

\section{Information sources and literature search}

To identify potentially relevant studies for inclusion, the following electronic databases were searched: MEDLINE; EMBASE; and the Cochrane Library. Since two systematic reviews have already been published on rapid reviews $[6,7]$, we limited our search from 2008 until May 2013. An experienced librarian (LP) drafted the literature searches based on the previous reviews, which was refined through team discussion. The MEDLINE search strategy is presented in Additional file 1: Appendix 1 and the other searches are available from the corresponding author upon request.

Our literature search was supplemented by targeted internet searches for unpublished rapid review reports posted on the websites of producers of rapid reviews. For this search, we took a random $10 \%$ sample of the unpublished rapid reviews available on the producers' websites. Often only the title was available for the rapid reviews, so, we focused inclusion to the full rapid review, if available. The reference lists of relevant reviews were scanned $[6,7]$, as were the reference lists of all included rapid reviews.

\section{Inclusion criteria}

Articles, papers, books, and reports were included if they evaluated, compared, used or described a rapid review according to the authors.

\section{Screening process}

The screening criteria were established $a$ priori (as outlined in our protocol) and calibrated amongst the team through a series of pilot tests. After $>90 \%$ agreement was observed, pairs of reviewers screened the literature search results independently, and discrepancies were resolved through discussion. All screening was performed using our online tool, synthesi.sr [9].

\section{Data items and data abstraction process}

A data abstraction form was developed $a$ priori and the draft form was calibrated amongst the team using a random sample of ten included studies. After this exercise, the data abstraction form was revised and all included studies were abstracted by two reviewers working independently. Discrepancies were resolved through discussion.

Data items included study characteristics (for example, first author, year of publication), terminology used to describe the rapid review, full citation of previous methods papers that were used to guide the rapid review design, timeframe (in months) for completing the rapid review, and operationalized steps of the rapid review, if reported. The rapid review type was categorized as an application (for example, a rapid review report), development (paper attempts to further refine the rapid review method), impact (examines the impact of rapid reviews) or comparison (compares the results of a rapid review to a systematic review). We abstracted the assessment of the rapid review approach, including accuracy of results, comprehensiveness, potential for risk of bias, timeliness, cost-effectiveness, and feasibility as reported by the publication authors. We also abstracted the skills or knowledge required to conduct the rapid review as reported by the authors.

\section{Synthesis}

To synthesize the descriptive results, we conducted qualitative analysis using NVivo 10 [10]. Content analysis was conducted by one team member (WZ) and verified by another team member (ACT) to synthesize common methodologies used across the included rapid 
reviews using a framework. The framework was developed by the review team and presented in Additional file 1: Appendix 2. The framework focused on the following steps for a rapid review: literature search (number of databases and grey literature); inclusion criteria (limited by date, language, and study design); screening (title/abstract and full-text); data abstraction; risk of bias/quality appraisal; and data synthesis. In order to depict the frequency of the terms used to describe the rapid reviews, a word cloud was created using Wordle, which is software that generates 'word clouds' from text that the user provides and places more emphasis on words that occur with greater frequency [11].

\section{Results}

\section{Literature search}

A total of 3,397 citations and 262 potentially relevant full-text papers were screened. Subsequently, 100 articles $[2,12-110]$ plus one companion report [111] fulfilled the eligibility criteria and were included [31] (Fig. 1). Forty-seven of the included papers were unpublished rapid reviews posted on websites $[13,24,29,31-36,39$, $45,47,50,52-57,62,63,66,68,70,73-75,77,81-83$, 86-94, 99, 100, 103, 104, 107, 109, 112].

\section{Rapid review characteristics and assessment}

The rapid reviews were published between 1997 and 2013, and 58 were conducted in Europe, while 20 were conducted in North America (Table 1, Additional file 1: Appendix 3). The type of articles included 84 application papers (two did not report any methods), seven development papers, six impact papers, and four comparison papers; one article [20] was categorized in two categories. Ten of the rapid reviews were reported in 5 pages or less, suggesting that they were brief reports or research letters. Most of the articles (73\%) did not report the duration of conduct for the rapid review. For the minority that reported this, the duration ranged from less than 1 month to 12 months, and 18 were between 1 and
6 months. For the application articles, $74 \%$ examined interventions, $12 \%$ charted the frequency of literature (for example, regarding outcomes or frameworks), $5 \%$ examined associations between exposure and disease, $5 \%$ assessed diagnosis or screening techniques, and $2 \%$ examined the patient experience or barriers/facilitators.

Sixty-five articles assessed rapid review characteristics (Table 2) [2, 12, 14-22, 24, 26-30, 32, 37-39, 41-43, $45-49,51-59,61,63,64,66,69,72-76,78-80,84,86$, $88-94,100,103-105,110]$. Sixty percent of the authors reported that the report was timely, $29 \%$ believed that the method had potential risk of bias, $23 \%$ deemed that the approach was accurate compared to a full systematic review, $8 \%$ believed the approach was comprehensive, $5 \%$ reported that the approach was cost-effective, and $6 \%$ believed it was a feasible approach.

\section{Terminology used to describe the rapid review method}

The most frequent term used to describe the rapid review approaches was 'rapid review', used in 34 of the included articles (Fig. 2). This was followed by 'rapid evidence assessment', which was used in 11 papers, 'rapid systematic review' in ten papers, and 'health technology assessment' or 'rapid health technology assessment' in six papers. All of the other terms occurred two times or less.

\section{Citation analysis}

Twenty-six $[2,12,13,17,20-22,27,28,30,40,42-44$, $48,49,61,76,78-80,84,88,103,105,110]$ articles provided citations of previous methods papers that were used to guide the rapid review method (Fig. 3, Additional file 1: Appendix 4). The citations were Ganann and colleagues [6] (cited in eight papers), Watt and colleagues [7, 111] (cited in seven papers), a Civil Service paper [113] (cited in four papers), Ehlers and colleagues [114] (cited in one paper), Armitage and colleagues [14] (cited in one paper), and Grant and colleagues [115] (cited in one paper).

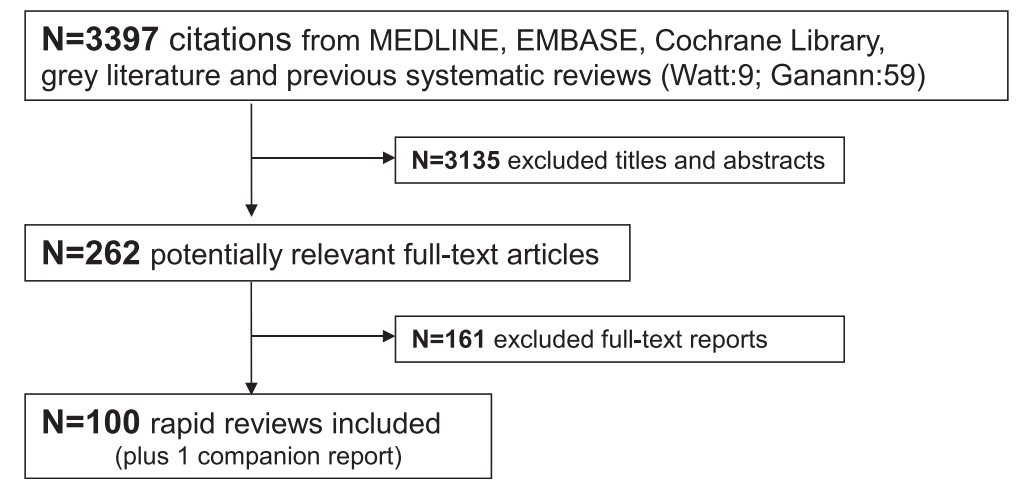

Fig. 1 Study flow diagram 
Table 1 Summary of study characteristics

\begin{tabular}{|c|c|}
\hline Study characteristics & $\begin{array}{l}\text { Number of rapid reviews } \\
(\mathrm{n}=100)^{\mathrm{a}}\end{array}$ \\
\hline \multicolumn{2}{|l|}{ Year of publication } \\
\hline $1997-2000$ & 2 \\
\hline $2001-2004$ & 10 \\
\hline $2005-2008$ & 30 \\
\hline 2009-2012 & 51 \\
\hline 2013 & 5 \\
\hline Not reported & 4 \\
\hline \multicolumn{2}{|l|}{ Continent } \\
\hline Europe (including UK) & 58 \\
\hline North America (Canada and United States) & 20 \\
\hline Australia & 15 \\
\hline Multiple continents & 3 \\
\hline Asia & 1 \\
\hline South America & 1 \\
\hline Not reported & 2 \\
\hline \multicolumn{2}{|l|}{ Article type ${ }^{b}$} \\
\hline Application (82 with methods) & 84 \\
\hline Development & 7 \\
\hline Impact & 6 \\
\hline Comparison & 4 \\
\hline \multicolumn{2}{|l|}{ Topic of review } \\
\hline Intervention & $62(74 \%)$ \\
\hline Frequency & $10(12 \%)$ \\
\hline Causal association & $4(5 \%)$ \\
\hline Diagnosis & $4(5 \%)$ \\
\hline \multirow[t]{2}{*}{ Patient experienceScreening } & $2(2 \%)$ \\
\hline & $2(2 \%)$ \\
\hline Not applicable & 16 \\
\hline \multicolumn{2}{|l|}{ Some methods reported } \\
\hline Yes & 82 \\
\hline No & 18 \\
\hline \multicolumn{2}{|l|}{ Review question } \\
\hline Clearly reported & 81 \\
\hline Unclear/not reported & 1 \\
\hline Not applicable & 18 \\
\hline
\end{tabular}

${ }^{a} 100$ relevant articles and one companion report (companion report not included in this table); ${ }^{\text {b }}$ one development article was also categorized as a comparison paper

Skills and knowledge required to conduct the rapid reviews Thirteen [16, 32, 39, 42, 46, 48, 49, 52, 79, 84, 88, 90, 94] of the included papers reported the skills and knowledge required to conduct the rapid reviews (Table 3). These were content experts in seven articles [16, 32, $42,48,49,79,90]$, information specialists in five articles
$[39,49,52,84,88]$, systematic review methodologists in four papers [16, 42, 48, 79], staff experienced in conducting reviews in four papers $[46,48,49,84]$, and knowledge users in three papers $[32,79,94]$.

\section{Operationalized steps to conduct the rapid review applications}

The 84 rapid review applications were categorized using our framework (Additional file 1: Appendix 2) and 50 unique methods were observed. Of these, only 16 occurred more than once; three approaches occurred five times $[21,36,40,44,45,47,53,54,56,57,65,75,83$, $91,92]$, another two occurred four times [18, 37, 39, 64, $86,93,99,107]$, three approaches were used three times $[49,51,58,61,62,69,73,76,81]$, and eight approaches occurred two times $[14,16,20,25,27,30,31,66-68,70$, $79,82,96,100,104]$. The characteristics of the rapid review approaches that occurred more than four times were analyzed (Table 4). Rapid Approach 1 had the most details reported, with $5 / 5$ papers mentioning that it was accurate and timely (but did not report the amount of time it took to conduct their rapid review), and had limited comprehensiveness.

Many of the steps used in the rapid reviews were not fully reported (Table 5, Additional file 1: Appendix 5). For example, $40 \%$ (33/82) did not report whether reference lists were scanned and $67 \%$ (55/82) did not report whether authors were contacted to obtain further material or information.

Streamlined methods that were used in the 82 rapid reviews included limiting the literature search to published literature $(24 \%)$ or one database $(2 \%)$, limiting inclusion criteria by date (68\%) or language (49\%), having one person screen and another verify or screen excluded studies (6\%), having one person abstract data and another verify (23\%), not conducting risk of bias/ quality appraisal (7 \%) or having only one reviewer conduct the quality appraisal (7\%), and presenting results as a narrative summary (78 \%) (Fig. 4).

\section{Comparing results from rapid reviews to systematic reviews}

Four studies were comparisons, providing details on differences in results between rapid reviews and systematic reviews [20, 31, 34, 106]. Cameron and colleagues identified rapid reviews from health technology assessment (HTA) organization websites and then conducted a literature search to identify systematic reviews on the same topic [31]. Eight rapid review products were identified on four different topics. However, the authors did not appraise the methodological quality of the systematic reviews, so it is unclear whether shortcuts were also taken in the included systematic reviews. The authors noted that the conclusions did not differ 
Table 2 Assessing the characteristics of rapid reviews compared to systematic reviews

\begin{tabular}{lllll}
\hline Characteristic assessed $(n=65)^{\text {a }}$ & Yes (\%) & Limited (\%) & Unknown (\%) & Not reported (\%) \\
\hline Accuracy & $15(23 \%)$ & $5(8 \%)$ & $3(5 \%)$ & $42(64 \%)$ \\
Comprehensiveness & $5(8 \%)$ & $46(71 \%)$ & $4(6 \%)$ & $10(15 \%)$ \\
Risk of bias & $19(29 \%)$ & $19(29 \%)$ & $3(5 \%)$ & $24(37 \%)$ \\
Timeliness & $39(60 \%)$ & $1(2 \%)$ & $1(2 \%)$ & $23(35 \%)$ \\
Cost-effectiveness & $3(5 \%)$ & 0 & 0 & $62(95 \%)$ \\
Feasibility & $4(6 \%)$ & $3(5 \%)$ & 0 & $58(89 \%)$ \\
\hline
\end{tabular}

${ }^{a} 65$ of the 100 studies reported this information

substantially between the rapid and systematic reviews. Corabian and colleagues compared six rapid review products (called 'technotes') with their final peerreviewed publications [34]. The authors found that the conclusions differed only in $1 / 6$ cases. Van de Velde and colleagues compared the results from their rapid review to a systematic review that was conducted by another group and published on the same topic [106]. Despite having literature searches that were conducted for the same dates, conflicting results were observed; the rapid review concluded that potato peel was effective for burns, while the systematic review concluded that potato peel was not effective for treating burns. Finally, Best and colleagues noted that two of the rapid reviews they conducted were in agreement with systematic reviews published at a later point in time on the same topic [20].

\section{Development papers on rapid reviews}

Seven papers proposed methods to refine the rapid review approach $[2,12,16,20,46,79,80]$. Best and colleagues (1997) described their experience conducting 63 rapid reviews for decision-making beginning in 1991, through the Development and Evaluation Committee in the UK [20]. Abrami and colleagues (2010) described ways to produce brief reviews efficiently, and presented a checklist for the conduct and reporting of brief reviews [12]. Bambra and colleagues (2010) described their experience conducting nine rapid reviews for the Secretary of State for Health [16]. Jahangirian and colleagues (2011) described their experience conducting five rapid reviews for the Research into Global Healthcare Tools consortium and proposed a framework for the conduct of rapid reviews [46]. Khangura and colleagues (2012) described their approach to the conduct of 11 rapid 


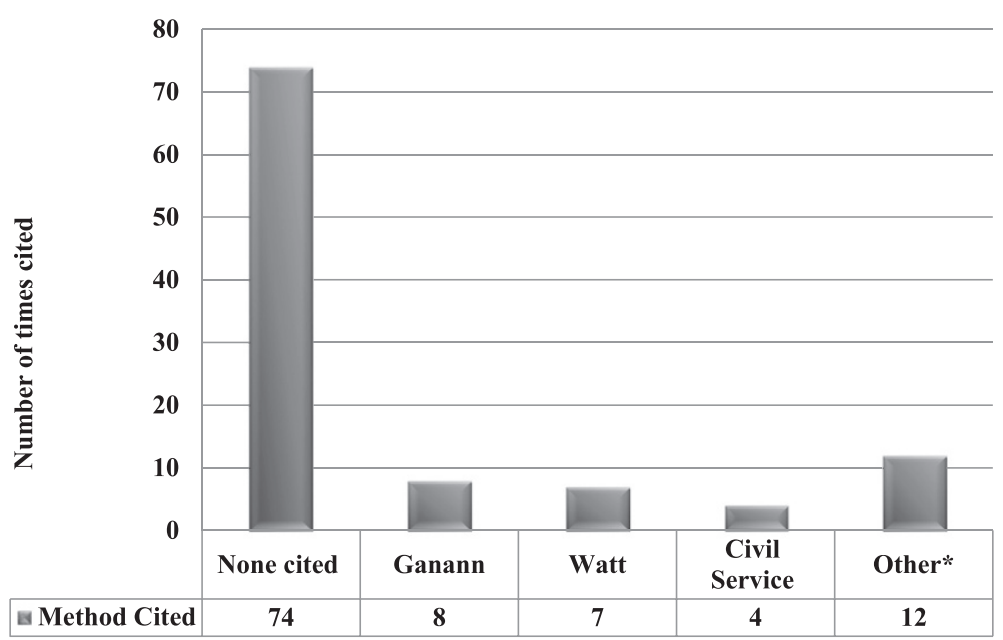

Fig. 3 Citation analysis. *Twenty-six papers referenced another seminal paper to establish their rapid review framework

reviews through the collaboration between the Ottawa Hospital Research Institute and the Champlain Local Health Integrated Network [2]. Thigpen and colleagues (2012) described their experience conducting rapid reviews using the 6-step Prevention Synthesis and Translation System process for the Division of Violence Prevention, National Center for Injury Prevention and Control at the Centers for Disease Control and Prevention [79]. Thomas and colleagues (2013) described their experience of conducting two rapid reviews for the UK Treasury to inform the 2006/07 Comprehensive Spending Review [80].

Guidance to streamline the rapid review process varied, yet some consistencies were observed (Table 6). For example, four papers suggested using integrated knowledge translation, in which researchers work closely with the knowledge users to complete the rapid review $[2,16,19,79]$. Four papers suggested the use of a research question with a limited scope $[12,16,80,110]$. Seven publications recommended streamlining the literature search $[2,12,16,46,79,80,110]$ and three suggested restricting the eligibility criteria [2, 12, 80]. Two papers provided suggestions for efficiently appraising risk of bias $[2,80]$ and none suggested conducting a meta-analysis as part of the rapid review.

Articles assessing the impact and use of rapid reviews Six papers examined the impact of rapid reviews on decision-making $[41-43,60,85,110]$. Hailey and

Table 3 Skills required to conduct a rapid review

\begin{tabular}{|c|c|c|c|c|c|}
\hline \multirow[b]{2}{*}{ Author, year } & \multicolumn{5}{|l|}{ Skills required ${ }^{a}$} \\
\hline & Content experts & Information specialists & Experienced staff & Methodologists & Knowledge users \\
\hline Bambra, 2010 & $\checkmark$ & & & $\checkmark$ & \\
\hline Brunton, 2013 & & $\checkmark$ & & & \\
\hline Carr, 2011 & $\checkmark$ & & & & \\
\hline Clark, 2003 & $\checkmark$ & & & & $\checkmark$ \\
\hline Foerster, 2007 & & $\checkmark$ & & & \\
\hline Hailey, 2009 & $\checkmark$ & & & $\checkmark$ & \\
\hline Jahangirian, 2011 & & & $\checkmark$ & & \\
\hline Kelly, 2011 & $\checkmark$ & & $\checkmark$ & $\checkmark$ & \\
\hline Konnyu, 2012 & $\checkmark$ & $\checkmark$ & $\checkmark$ & & \\
\hline Low, 2006 & & $\checkmark$ & & & \\
\hline Thigpen, 2012 & $\checkmark$ & & & $\checkmark$ & $\checkmark$ \\
\hline Tripney, 2011 & & & & & $\checkmark$ \\
\hline York, 2011 & & $\checkmark$ & $\checkmark$ & & \\
\hline
\end{tabular}

${ }^{\mathrm{a}}$ As reported by the authors 
Table 4 Evaluation of rapid review approaches occurring more than four times

\begin{tabular}{|c|c|c|c|c|c|c|c|c|}
\hline Rapid review approach & Author, year & $\begin{array}{l}\text { Duration of } \\
\text { review }\end{array}$ & Accuracy & Comprehensiveness & Risk of bias & Timeliness & Cost-effectiveness & Feasibility \\
\hline \multirow{5}{*}{$\begin{array}{l}\text { Approach 1. Literature search: searched more than one database, } \\
\text { limited to published sources only. Search limit: limited by both } \\
\text { date and language. Screening: title/abstract and full-text screening } \\
\text { performed by one reviewer only. Data abstraction: one person } \\
\text { abstracted data, while another person verified the data risk of bias } \\
\text { assessment; one person assessed risk of bias, while another person } \\
\text { verified the risk of bias assessment }\end{array}$} & Blank, 2012 & NR & Accurate & Limited & Potential ROB & Timely & NR & NR \\
\hline & Maddern, NR & NR & Accurate & Limited & NR & Timely & NR & NR \\
\hline & Maddern, NR & NR & Accurate & Limited & NR & Timely & NR & NR \\
\hline & Maddern, 2008 & NR & Accurate & Limited & $N R$ & Timely & $N R$ & NR \\
\hline & Maddern, NR & NR & Accurate & Limited & $N R$ & Timely & NR & NR \\
\hline \multirow{5}{*}{$\begin{array}{l}\text { Approach 2. Literature search: used previous review(s) as starting } \\
\text { point; searched published sources only. Search limit: no language } \\
\text { or date limits applied. Screening: title/abstract and full-text } \\
\text { screening performed by one reviewer only. Data abstraction: } \\
\text { data abstraction performed by one reviewer only. Risk of bias } \\
\text { assessment: not performed }\end{array}$} & Van de Velde, 2011 & 1 month & NR & NR & NR & NR & NR & NR \\
\hline & Mitchell, 2011 & 3-4 days & $\begin{array}{l}\text { Unknown } \\
\text { accuracy }\end{array}$ & Limited & NR & Timely & Cost-effective & NR \\
\hline & $\begin{array}{l}\text { Government Social } \\
\text { Research, } 2007\end{array}$ & 8-12 weeks & $N R$ & $N R$ & NR & NR & NR & $N R$ \\
\hline & Dixon-Woods, 2012 & NR & NR & NR & Potential ROB & NR & NR & NR \\
\hline & Van Brabandt, 2008 & NR & $N R$ & NR & $N R$ & NR & NR & $N R$ \\
\hline \multirow{4}{*}{$\begin{array}{l}\text { Approach 3. Literature search: searched more than one database, } \\
\text { searched both published and grey literature. Search limit: limited } \\
\text { by both date and language. Screening: title/abstract and full-text } \\
\text { screening performed by one reviewer only. Data abstraction: } \\
\text { data abstraction performed by one reviewer only. Risk of bias } \\
\text { assessment: not performed }\end{array}$} & Foerster, 2007 & NR & $N R$ & NR & $N R$ & NR & NR & $N R$ \\
\hline & Beck, 2012 & NR & NR & $N R$ & NR & Timely & NR & NR \\
\hline & Rissel, 2012 & $N R$ & NR & NR & $N R$ & NR & NR & NR \\
\hline & $\begin{array}{l}\text { ASERNIP - Surgical, } \\
2009\end{array}$ & $N R$ & $N R$ & Limited & Potential ROB & NR & $N R$ & NR \\
\hline \multirow{5}{*}{$\begin{array}{l}\text { Approach 4. Literature search: searched more than one database, } \\
\text { searched both published and grey literature. Search limit: limited } \\
\text { by either date or language. Screening: title/abstract and full-text } \\
\text { screening performed by one reviewer only. Data abstraction: } \\
\text { data abstraction performed by one reviewer only. Risk of bias } \\
\text { assessment: not performed }\end{array}$} & Hildon, 2012 & NR & $N R$ & NR & $N R$ & NR & NR & NR \\
\hline & Jolliffe, 2008 & NR & $\begin{array}{l}\text { Limited } \\
\text { accuracy }\end{array}$ & Limited & Potential ROB & timely & NR & NR \\
\hline & De Laet, 2008 & $N R$ & $N R$ & $N R$ & $N R$ & NR & $N R$ & NR \\
\hline & Hulstaert, 2009 & NR & $N R$ & Limited & $N R$ & NR & NR & NR \\
\hline & Moran, 2011 & NR & $N R$ & $N R$ & $N R$ & NR & NR & $N R$ \\
\hline \multirow{5}{*}{$\begin{array}{l}\text { Approach 5. Literature search: searched more than one database, } \\
\text { searched both published and grey literature. Search limit: limited } \\
\text { by date only; no language limits applied. Screening: title/abstract } \\
\text { and full-text screening performed by one reviewer only. Data } \\
\text { abstraction: data abstraction performed by one reviewer only. } \\
\text { Risk of bias assessment: risk of bias assessed by one reviewer only }\end{array}$} & Phillipson, 2012 & NR & NR & NR & NR & NR & NR & NR \\
\hline & Geddes, 2011 & NR & $N R$ & NR & $N R$ & NR & $N R$ & NR \\
\hline & Doran, 2013 & NR & NR & Unknown & Potential ROB & NR & NR & NR \\
\hline & Vlayen, 2006 & NR & NR & NR & NR & $N R$ & NR & NR \\
\hline & Singh, 2006 & 3 weeks & NR & Limited & NR & NR & NR & NR \\
\hline
\end{tabular}

NR, not reported; ROB, risk of bias 
Table 5 Summary of rapid review streamlined approaches ( $\mathrm{n}=82$ application studies)

\begin{tabular}{|c|c|c|}
\hline \multicolumn{2}{|l|}{ Rapid review methods } & Count (\%) \\
\hline \multicolumn{3}{|l|}{ General } \\
\hline \multicolumn{3}{|l|}{ Duration of review } \\
\hline & $>6$ months & $3(4 \%)$ \\
\hline & $\leq 6$ months & $19(23 \%)$ \\
\hline & Vot reported & $60(73 \%)$ \\
\hline \multicolumn{3}{|l|}{ Published protocol } \\
\hline & Mentioned & $2(2 \%)$ \\
\hline & Vot mentioned & $80(98 \%)$ \\
\hline \multicolumn{3}{|l|}{ Review question } \\
\hline & Clearly reported & $81(99 \%)$ \\
\hline & Jnclear/inferred & $1(1 \%)$ \\
\hline \multicolumn{3}{|c|}{ Identifying relevant studies } \\
\hline \multicolumn{3}{|l|}{ Databases searched } \\
\hline & Searched more than one database & $67(82 \%)$ \\
\hline & Searched one database only & $2(2 \%)$ \\
\hline & $\begin{array}{l}\text { Jsed a previous review(s) as } \\
\text { starting point }\end{array}$ & $8(10 \%)$ \\
\hline & Vot reported & $5(6 \%)$ \\
\hline
\end{tabular}

Grey literature

Searched grey literature

$57(70 \%)$

No grey literature search

$20(24 \%)$

Not reported

$5(6 \%)$

Search strategy

$\begin{array}{ll}\text { Clearly reported } & 64(78 \%) \\ \text { Unclear } & 7(9 \%) \\ \text { Not reported } & 11(13 \%)\end{array}$

Scanned references

Yes

No

Not reported

Contacted authors

$\begin{array}{ll}\text { Yes } & 18(22 \%) \\ \text { No } & 9(11 \%) \\ \text { Not reported } & 55(67 \%)\end{array}$

Limits applied

Date

$$
\begin{aligned}
& \text { No limit } \\
& \text { Limited by date } \\
& \text { Not reported }
\end{aligned}
$$

Language

$$
\text { No limit }
$$

Limited by language

Not reported

$10(12 \%)$ $56(68 \%)$

$16(20 \%)$

14 (17\%)

$40(49 \%)$

$28(34 \%)$
Table 5 Summary of rapid review streamlined approaches ( $\mathrm{n}=82$ application studies) (Continued)

Selecting relevant studies

Titles and abstracts

Two or more independent

$28(34 \%)$

reviewers

$4(5 \%)$

One reviewer and one verifier

$15(18 \%)$

One reviewer only

$20(24 \%)$

Done but unclear number of reviewers

$1(1 \%)$

Not done

$14(17 \%)$

Full-texts

Not reported

$20(24 \%)$

Two or more independent

reviewers

$5(6 \%)$

One reviewer only

$9(11 \%)$

Done but unclear number of

reviewers

$23(28 \%)$

Not done

$1(1 \%)$

Not reported

$24(29 \%)$

Data abstraction and quality appraisal

Data abstraction

Two or more independent
reviewers
One reviewer and one verifier
One reviewer only

$8(10 \%)$

$19(23 \%)$

$6(7 \%)$

Done but unclear number of reviewers

$30(37 \%)$

Not done

Not reported

Quality appraisal

Two or more independent

$14(17 \%)$ reviewers

One reviewer and one verifier

$11(13 \%)$

One reviewer only

$6(7 \%)$

Done but unclear number of reviewers

Not done

Data synthesis

Data synthesis

Meta-analysis or clear reasons

$18(22 \%)$ for not pooling results

Narrative/descriptive summary only

$64(78 \%)$ colleagues (2000) examined the impact of 20 rapid review products [43] and found that 14 had an influence on policy decision-making, four provided guidance, and two had no perceived impact. McGregor 


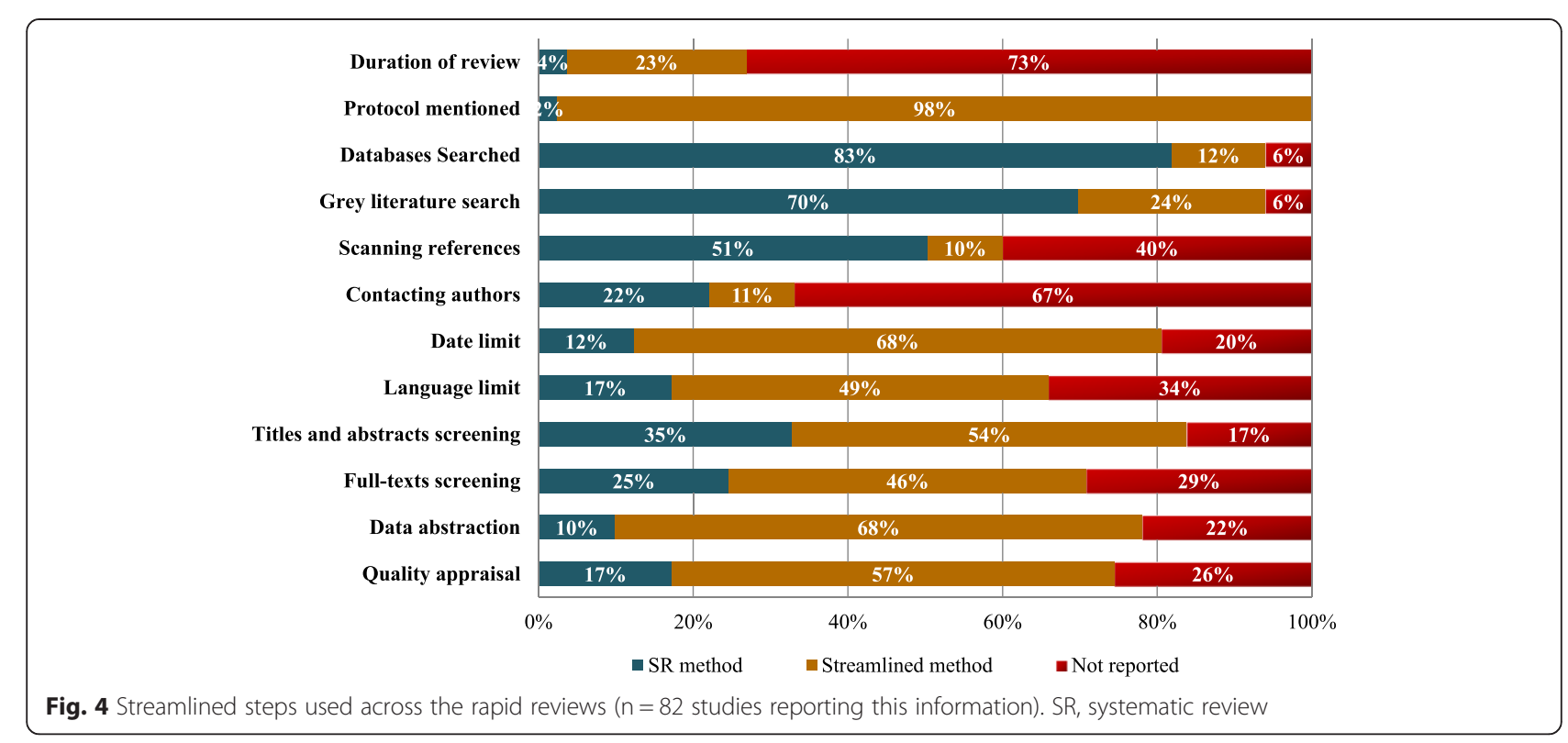

and Brophy (2005) evaluated the success of the conduct of 16 rapid reviews for a hospital rapid review service [60]. The results of all 16 products were directly implemented in the hospital, saving approximately \$3 million per year. Hailey (2006) wrote a paper summarizing the impact of HTA in general, as well as related to rapid HTA. Overall, it was concluded that these reports can influence decision-making. Hailey (2009) conducted a survey of HTA organizations to examine the use of rapid reviews for decision-making [42]. Fifteen rapid review products were included; all influenced a decision, including using the rapid review for reference material $(67 \%)$ and directly using the rapid review's conclusions for the decision (53\%). Zechmeister (2012) examined the impact of 58 rapid assessments and observed that 56 of these products were directly used for reimbursement decisions and two were used for disinvestment decisions [85]. Finally, Batten (2012) wrote an editorial discussing how rapid reviews can be used by school nurses [110].

\section{Discussion}

Our results suggest that the conduct of rapid reviews is recondite across the literature. Through our study, 50 different rapid review approaches were identified and only 16 occurred more than once. Furthermore, many different terms were used to describe a rapid review, making the identification of these types of knowledge synthesis products difficult.

Using a framework of rapid review methods, we observed numerous strategies employed to conduct reviews in a streamlined manner. These included not using a protocol, limiting the literature search, limiting inclusion criteria, only having one person screen the literature search results, not conducting quality appraisal, and not conducting a meta-analysis. In general, combining multiple shortcuts led to a timelier conduct of the review.

Only four of the included studies compared the results of rapid reviews to systematic reviews. Three of these found that the results for both knowledge synthesis products were in agreement. However, the results of these studies should be interpreted with caution because a very small sample of reviews were included (ranging from 1 to 8 ) and none of these were prospectively conducted. The latter is of particular importance, since it is unclear whether the authors of the full systematic reviews used the rapid review as a starting point to identify articles for inclusion (or vice versa). Interestingly, none of the included studies compared the results across rapid reviews on the same topic. Such a study may provide further clarity into the impact of streamlining different steps on the risk of bias and comprehensiveness of the review.

Seven papers provided recommendations on making rapid reviews more efficient. Consistent guidance included using an integrated knowledge translation approach, limiting the scope of the question and literature search, and not conducting a meta-analysis. Furthermore, six papers examined the impact of rapid reviews on decision-making and all found that they were valuable products. These results suggest that decisionmakers are currently using rapid reviews to inform their decision-making processes. Further supporting this observation was the recent Canadian Agency for Drugs and Technologies in Health Rapid review summit [116], 
Table 6 Guidance provided in development papers on rapid reviews

\begin{tabular}{|c|c|c|c|c|c|c|c|c|}
\hline Author, year & $\begin{array}{l}\text { Overall approach to } \\
\text { the rapid review }\end{array}$ & Question & Literature search & Screening & Data abstraction & Risk of bias & Synthesis & $\begin{array}{l}\text { Dissemination/knowledge } \\
\text { translation }\end{array}$ \\
\hline Best, 1997 & Use a fixed structure & $\begin{array}{l}\text { Identified by } \\
\text { purchasers and } \\
\text { providers }\end{array}$ & $\begin{array}{l}\text { Electronic databases } \\
\text { and grey literature }\end{array}$ & Not reported & $\begin{array}{l}\text { Limit the outcomes } \\
\text { to cost-effectiveness }\end{array}$ & Not reported & $\begin{array}{l}\text { Descriptive. Focus } \\
\text { on benefits/disbenefits } \\
\text { and costs/savings }\end{array}$ & $\begin{array}{l}\text { Report provided to the } \\
\text { committee who meets } \\
\text { every } 3 \text { months to } \\
\text { make decisions }\end{array}$ \\
\hline Abrami, 2010 & $\begin{array}{l}\text { Use of a larger staff } \\
\text { to conduct the } \\
\text { review in a timelier } \\
\text { manner. Use of } \\
\text { tools to make the } \\
\text { process more } \\
\text { efficient }\end{array}$ & $\begin{array}{l}\text { Specific research } \\
\text { question }\end{array}$ & $\begin{array}{l}\text { Updating or } \\
\text { expanding an } \\
\text { existing review }\end{array}$ & $\begin{array}{l}\text { Use strict inclusion } \\
\text { criteria. Only screen } \\
\text { a random sample } \\
\text { of results. Bypassing } \\
\text { steps that check for } \\
\text { inter-rater agreement }\end{array}$ & Not reported & Not reported & $\begin{array}{l}\text { Descriptive only. } \\
\text { Use of vote counting. } \\
\text { Charting results only }\end{array}$ & Not reported \\
\hline Bambra, 2010 & Not reported & Limited scope & $\begin{array}{l}\text { Rapid search of the } \\
\text { literature to limited } \\
\text { key words and } \\
\text { databases. Restrict } \\
\text { searches by date, } \\
\text { accessibility, and } \\
\text { policy relevance }\end{array}$ & Not reported & Not reported & $\begin{array}{l}\text { Appraise } \\
\text { evidence }\end{array}$ & $\begin{array}{l}\text { Develop key } \\
\text { recommendations }\end{array}$ & $\begin{array}{l}\text { Refine key recommendations } \\
\text { using a Delphi approach } \\
\text { with end-users }\end{array}$ \\
\hline Jahangirian, 2011 & $\begin{array}{l}\text { Incremental and } \\
\text { iterative }\end{array}$ & Not reported & $\begin{array}{l}\text { Forward citation } \\
\text { searching and } \\
\text { backward citation } \\
\text { searching }\end{array}$ & $\begin{array}{l}\text { 3-stage screening } \\
\text { phase (filtering, } \\
\text { sampling, and sifting) }\end{array}$ & $\begin{array}{l}\text { Use graphical tools } \\
\text { that allow the } \\
\text { charting of the } \\
\text { literature }\end{array}$ & Not reported & Not reported & Not reported \\
\hline Khangura, 2012 & $\begin{array}{l}\text { Work closely with } \\
\text { end-users using } \\
\text { integrated knowledge } \\
\text { translation }\end{array}$ & $\begin{array}{l}1-2 \text { hours to } \\
\text { refine question } \\
\text { with policy-makers. } \\
\text { Iterative process }\end{array}$ & $\begin{array}{l}\text { Targeted literature } \\
\text { searches. Includes } \\
\text { published and } \\
\text { unpublished } \\
\text { literature. Focus } \\
\text { inclusion on } \\
\text { systematic reviews }\end{array}$ & $\begin{array}{l}\text { Limited to English. } \\
\text { Liberal accelerated }^{\mathrm{b}}\end{array}$ & Not reported & $\begin{array}{l}\text { Use the level of } \\
\text { evidence based } \\
\text { on a modified } \\
\text { framework } \\
\text { established by } \\
\text { the Cochrane } \\
\text { Musculoskeletal } \\
\text { Group }\end{array}$ & $\begin{array}{l}\text { Descriptive synthesis } \\
\text { only. Concise report; } \\
\text { 1-page brief }\end{array}$ & $\begin{array}{l}\text { Collaborative approach. } \\
\text { Use feedback on previous } \\
\text { products to improve } \\
\text { future products }\end{array}$ \\
\hline Thigpen, 2012 & $\begin{array}{l}\text { Work closely with } \\
\text { end-users using } \\
\text { integrated knowledge } \\
\text { translation }\end{array}$ & $\begin{array}{l}\text { Consult with } \\
\text { end-user to } \\
\text { decide on the } \\
\text { topic }\end{array}$ & $\begin{array}{l}\text { Internal and } \\
\text { external experts } \\
\text { engaged to focus } \\
\text { literature search }\end{array}$ & $\begin{array}{l}\text { Researchers and } \\
\text { end-users engaged } \\
\text { in establishing } \\
\text { relevance }\end{array}$ & $\begin{array}{l}\text { Focus on common } \\
\text { components and } \\
\text { key messages }\end{array}$ & Not reported & $\begin{array}{l}\text { Distill the research } \\
\text { literature }\end{array}$ & $\begin{array}{l}\text { Interpretation guided by } \\
\text { end-users to ensure } \\
\text { relevance, understanding, } \\
\text { and actionable knowledge. } \\
\text { Use of 2-4-paged } \\
\text { user-friendly briefs }\end{array}$ \\
\hline Thomas, 2013 & $\begin{array}{l}\text { Require an experienced } \\
\text { team in systematic } \\
\text { reviews to conduct the } \\
\text { rapid reviews. Prioritize } \\
\text { rapid reviews for } \\
\text { urgent decisions }\end{array}$ & $\begin{array}{l}\text { Clearly defined. } \\
\text { Limited scope. } \\
\text { Limiting stakeholder } \\
\text { involvement to } \\
\text { provide insight into } \\
\text { the question and } \\
\text { protocol }\end{array}$ & $\begin{array}{l}\text { Targeted searches } \\
\text { of key databases }\end{array}$ & $\begin{array}{l}\text { Limiting inclusion } \\
\text { to English papers. } \\
\text { Only one person } \\
\text { screens the literature } \\
\text { results and another } \\
\text { screens random } \\
\text { sample or list of } \\
\text { excludes }\end{array}$ & $\begin{array}{l}\text { Mapping study } \\
\text { characteristics. } \\
\text { Focusing abstraction } \\
\text { on key interventions } \\
\text { and specific study } \\
\text { designs }\end{array}$ & $\begin{array}{l}\text { Selecting key } \\
\text { elements of } \\
\text { quality appraisal } \\
\text { tools and only } \\
\text { appraising these }\end{array}$ & $\begin{array}{l}\text { Use a framework } \\
\text { synthesis }\end{array}$ & Not reported \\
\hline
\end{tabular}


for which a large number of international decisionmaking organizations were in attendance.

Across the application papers, many of the methods were poorly reported suggesting that improvement in the reporting of rapid reviews is warranted. Thorough reporting of the methods is important because it is difficult to judge the bias of these reports without fully understanding what shortcuts were taken. As well, transparent reporting allows the reproducibility of research. It is important to note that $10 \%$ of the included papers were reported in 5 pages or less, suggesting that perhaps there was insufficient room to report the methods fully.

Prior to establishing a quality of reporting guidelines for rapid reviews, a common terminology and definition is required [117]. Some of the team members are currently involved with research that is attempting to tackle this issue. At the bare minimum, one of the included papers provided a checklist to examine the reporting of rapid reviews [12], which can be used by producers of rapid reviews to ensure their reports are reported in a consistent manner.

We have also conducted other research on rapid reviews that builds on this scoping review [118]. Specifically, we conducted an international survey of 40 rapid review producers who identified several rapid review approaches, such as updating the literature search of previous reviews and limiting the search strategy by date of publication. Most of the rapid review products were conducted within 12 weeks. A modified Delphi approach was used to include input from 113 stakeholders (for example, researchers, policy-makers, industry, journal editors, and healthcare providers) to agree upon an attractive rapid review method that would be used in a future comparative study. The stakeholders ranked the following method as being the most feasible, timely, and having a low perceived risk of bias: literature search limited by date and language; study selection by one reviewer only; and data abstraction and quality appraisal conducted by one reviewer and verified by a second reviewer. We are currently in the process of seeking funding of a comparative study to test the accuracy of this rapid review approach versus the gold standard, systematic review.

A recent project on rapid reviews was commissioned by the Agency for Healthcare Research and Quality in the United States $[119,120]$. The authors summarized evidence from 12 review articles of rapid reviews [120], as well as 35 different rapid reviews produced by 20 different organizations [119]. This information was obtained through literature searches and key informant interviews with 18 individuals who had experience of conducting rapid reviews. The authors are currently conducting interviews with policy-makers to obtain their perceptions on rapid reviews, including their utility and importance.
Our scoping review has some limitations. To make our review more feasible, we were only able to include a random sample of rapid reviews from websites of rapid review producers. Further adding to this issue is that many rapid reviews contain proprietary information and are not publicly available. As such, our results are only likely generalizable to rapid reviews that are publicly available. Furthermore, this scoping review was an enormous undertaking and our results are only up to date as of May 2013. However, we believe that our results provide important information on rapid reviews and ours is the most comprehensive scoping review that we are currently aware of.

\section{Conclusions}

In conclusion, numerous rapid review approaches were identified and few were used consistently in the literature. Poor quality of reporting was observed. Further research on rapid reviews is warranted. In particular, the consequences of various methodological shortcuts should be investigated. This could be examined through a prospective study comparing the results of rapid reviews to those obtained through systematic reviews on the same topic. Team members are currently seeking funding to conduct such a study and it is hoped that our results will provide pertinent information on the utility and risk of bias of rapid reviews.

\section{Additional file}

Additional file 1: Includes five appendices with supplementary data.

(PDF 603 kb)

\section{Abbreviations}

HTA: Health technology assessment; NR: Not reported; ROB: Risk of bias; SR: Systematic review.

\section{Competing interests}

The authors declare that they have no competing interests.

\section{Authors' contributions}

ACT conceived the study, obtained funding for the study, participated in all pilot tests of study eligibility and data abstraction, helped develop the

framework of rapid reviews, interpreted the data, and wrote the manuscript. JA coordinated the study, screened citations and full-text articles for inclusion, abstracted, coded, analyzed the data, and edited the manuscript. WZ verified and coded the data, conducted content analysis, helped develop the framework, and edited the manuscript. LS screened citations and full-text articles, abstracted data, and edited the manuscript. MG abstracted and verified the data, and edited the manuscript. JDI abstracted data and edited the manuscript. LP screened citations and full-text articles, abstracted some data, conducted the literature search, and edited the manuscript. $\mathrm{BH}$ and DM helped obtain funding for the study, helped conceive the study, and edited the manuscript. SES conceived the study, obtained funding for the study, participated in pilot tests of eligibility criteria, and edited the manuscript. All authors read and approved the final manuscript.

\section{Acknowledgements}

The study was funded by a Canadian Institutes of Health Research (CIHR) Operating Grant (grant \# DC0190GP, application \# 294284). ACT and BH hold a CIHR/Drug Safety and Effectiveness Network New Investigator Award, DM 
holds a University of Ottawa Research Chair, and SES holds a Tier 1 Canada Research Chair in Knowledge Translation.

We thank Drs Donna Ciliska and Diana Sherifali who provided support and expertise in rapid reviews and knowledge translation on our systematic review protocol. We also thank Ana Guzman for formatting the paper.

\section{Author details}

${ }^{1}$ Li Ka Shing Knowledge Institute of St Michael's Hospital, 209 Victoria Street, East Building, Room 716, Toronto, ON M5B 1 W8, Canada. ${ }^{2}$ Epidemiology Division, Dalla Lana School of Public Health, University of Toronto, 6th Floor, 155 College Street, Toronto, ON M5T 3 M7, Canada. ${ }^{3}$ Institute for Health Policy Management and Evaluation, University of Toronto, 4th Floor, 155 College Street, Toronto, ON M5T 3 M6, Canada. ${ }^{4}$ Ottawa Hospital Research Institute, Ottawa Methods Centre, Ottawa, ON, Canada. ${ }^{5}$ Department of Medicine, Faculty of Medicine, University of Toronto, 27 King's College Circle, Toronto, ON M5S 1A1, Canada.

\section{Received: 6 July 2015 Accepted: 28 August 2015 Published online: 16 September 2015}

\section{References}

1. Tricco AC, Tetzlaff J, Moher D. The art and science of knowledge synthesis. J Clin Epidemiol. 2011;64:11-20. doi:10.1016/j.jclinepi.2009.11.007.

2. Khangura S, Konnyu K, Cushman R, Grimshaw J, Moher D. Evidence summaries: the evolution of a rapid review approach. Syst Rev. 2012;1:10. doi:10.1186/2046-4053-1-10.

3. Higgins JPT. Green S (Eds). Cochrane handbook for systematic reviews of interventions. Version 5.1.0 (updated March 2011). Oxford: The Cochrane Collaboration; 2011.

4. Petticrew M, Roberts $H$. Systematic reviews in the social sciences: a practical guide. Malden, MA: Blackwell Publishing Co.; 2006.

5. Antman EM, Lau J, Kupelnick B, Mosteller F, Chalmers TC. A comparison of results of meta-analyses of randomized control trials and recommendations of clinical experts. Treatments for myocardial infarction. JAMA. 1992;268:240-8.

6. Ganann R, Ciliska D, Thomas H. Expediting systematic reviews: methods and implications of rapid reviews. Implement Sci. 2010;5:56. doi:10.1186/1748-5908-5-56

7. Watt A, Cameron A, Sturm L, Lathlean T, Babidge W, Blamey S, et al. Rapid reviews versus full systematic reviews: an inventory of current methods and practice in health technology assessment. Int J Technol Assess Health Care. 2008;24:133-9. doi:10.1017/S0266462308080185.

8. Arksey H, O'Malley L. Scoping studies: towards a methodological framework. Int J Soc Res Methodol. 2005:8:19-32. doi:10.1080/1364557032000119616.

9. synthesi.sr. http://knowledgetranslation.ca/sysrev/login.php.

10. NVivo 10 for Windows. http://www.qsrinternational.com/products_nvivo.aspx.

11. Feinberg J. Wordle. http://www.wordle.net.

12. Abrami PC, Borokhovski E, Bernard RM, Wade CA, Tamim R, Persson T, et al. Issues in conducting and disseminating brief reviews of evidence. Evid Policy. 2010:6:371-89. doi:10.1332/174426410X524866.

13. Adi Y, Bayliss S, Taylor R. Systematic review of clinical effectiveness and costeffectiveness of radiofrequency ablation for the treatment of varicose veins. Birmingham: West Midlands Health Technology Assessment Collaboration; 2004. http://www.birmingham.ac.uk/Documents/college-mds/haps/projects/ WMHTAC/REPreports/2004/varicoseveins.pdf.

14. Armitage A, Keeble-Ramsay D. The rapid structured literature review as a research strategy. US-China Education Review. 2009;6:27-38.

15. Attree P, French B, Milton B, Povall S, Whitehead M, Popay J. The experience of community engagement for individuals: a rapid review of evidence. Health Soc Care Comm. 2011;19:250-60. doi:10.1111/ j.1365-2524.2010.00976.x.

16. Bambra C, Joyce KE, Bellis MA, Greatley A, Greengross S, Hughes S, et al. Reducing health inequalities in priority public health conditions: using rapid review to develop proposals for evidence-based policy. J Public Health (Oxf). 2010;32:496-505. doi:10.1093/pubmed/fdq028.

17. Barnighausen $T$, Tanser $F$, Dabis F, Newell ML. Interventions to improve the performance of HIV health systems for treatment-as-prevention in sub-Saharan Africa: the experimental evidence. Curr Opin HIV AIDS. 2012;7:140-50. doi:10.1097/COH.0b013e32834fc1df.

18. Beck CR, Sokal R, Arunachalam N, Puleston R, Cichowska A, Kessel A, et al. Neuraminidase inhibitors for influenza: a review and public health perspective in the aftermath of the 2009 pandemic. Influenza Other Respir Viruses. 2013;7:14-24. doi:10.1111/irv.12048.

19. Best A, Greenhalgh T, Lewis S, Saul JE, Carroll S, Bitz J. Large-system transformation in health care: a realist review. Milbank Q. 2012;90:421-56. doi:10.1111/j.1468-0009.2012.00670.x.

20. Best L, Stevens A, Colin-Jones D. Rapid and responsive health technology assessment: the development and evaluation process in the South and West region of England. J Clin Effec. 1997;2:51-6.

21. Blank L, Coster J, O'Cathain A, Knowles E, Tosh J, Turner J, et al. The appropriateness of, and compliance with, telephone triage decisions: a systematic review and narrative synthesis. J Adv Nurs. 2012;68:2610-21. doi:10.1111/j.1365-2648.2012.06052.x.

22. Boycott N, Schneider J, McMurran M. Additional interventions to enhance the effectiveness of individual placement and support: a rapid evidence assessment. Rehabil Res Pract. 2012;2012:382420. doi:10.1155/2012/382420.

23. Brearley SG, Stamataki Z, Addington-Hall J, Foster C, Hodges L, Jarrett N, et al. The physical and practical problems experienced by cancer survivors: a rapid review and synthesis of the literature. Eur J Oncol Nurs. 2011;15:204-12. doi:10.1016/j.ejon.2011.02.005.

24. Brown A, Coyle D, Cimon K, Farrah K. Hip protectors in long-term care: a clinical and cost-effectiveness review and primary economic evaluation. Ottawa, ON: Canadian Agency for Drugs and Technologies in Health; 2008. http://www.cadth.ca/media/pdf/I3015_Hip_Protectors_ Long_Term_Care_tr_e.pdf.

25. Bryant SL, Gray A. Demonstrating the positive impact of information support on patient care in primary care: a rapid literature review. Health Info Libr J. 2006;23:118-25. doi:10.1111/j.1471-1842.2006.00652.x.

26. Bullock SH, Jones BH, Gilchrist J, Marshall SW. Prevention of physical training-related injuries recommendations for the military and other active populations based on expedited systematic reviews. Am J Prev Med. 2010;38:S156-81. doi:10.1016/j.amepre.2009.10.023.

27. Bungay $H$, Vella-Burrows $T$. The effects of participating in creative activities on the health and well-being of children and young people: a rapid review of the literature. Perspect Public Health. 2013;133:44-52. doi:10.1177/1757913912466946.

28. Burls A, Clark W, Stewart T, Preston C, Bryan S, Jefferson T, et al. Zanamivir for the treatment of influenza in adults: a systematic review and economic evaluation. Health Technol Assess. 2002;6:9.

29. Butler G, Hodgkinson J, Holmes E, Marshall S. Evidence based approaches to reducing gang violence: a rapid evidence assessment for Aston and Handsworth Operational Group. Birmingham: Government Office West Midlands and Home Office Regional Research Team; 2004. http:// www.civilservice.gov.uk/wp-content/uploads/2011/09/rea_gang_ violence_tcm6-7377.pdf.

30. Butt $S$, Chou S, Browne K. A rapid systematic review on the association between childhood physical and sexual abuse and illicit drug use among males. Child Abuse Rev. 2011;20:6-38. doi:10.1002/car.1100.

31. Cameron A, Watt A, Lathlean T, Sturm T. Rapid versus full systematic reviews: an inventory of current methods and practice in Health Technology Assessment. ASERNIP-S report number 60. Adelaide: Australian Safety and Efficacy Register of New Interventional Procedures - Surgical (ASERNIP-S); 2007. http://www.surgeons.org/ media/297941/rapidvsfull2007_systematicreview.pdf.

32. Clark W, Jobanputra P, Barton P, Burls A. The clinical and cost-effectiveness of anakinra for the treatment of rheumatoid arthritis in adults. Birmingham: West Midlands Health Technology Assessment Collaboration; 2003. http://www.nice.org.uk/guidance/ta72/documents/assessment-reportthe-clinical-and-costeffectiveness-of-anakinra-for-the-treatment-ofrheumatoid-arthritis-in-adults-2.

33. Coomber R, Millward L, Chambers J, Warm D. A rapid interim review of the 'grey' literature on risky behaviour in young people aged 11-18 with a special emphasis on vulnerable groups. London: Health Development Agency; 2004.

34. Corabian P, Harstall C. Rapid assessments provide acceptable quality advice. Annu Meet Int Soc Technol Assess Health Care Int Soc Technol Assess Health Care Meet. 2002;18:Abstract 70.

35. Cummins C, Connock M, Fry-Smith A, Burls A. A rapid review of new drug treatments for juvenile idiopathic arthritis: Etanercept. Birmingham: West Midlands Development and Evaluation Service, University of Birmingham; 2001. http://www.nice.org.uk/guidance/ta35/documents/assessment-reportfor-etanercept-for-juvenile-idiopathic-arthritis-2. 
36. De Laet C, Obyn C, Ramaekers D, Van De Sande S, Neyt M. Hyperbaric oxygen therapy: a rapid assessment. KCE reports 74C. Brussels: Health Technology Assessment (HTA) and Belgian Health Care Knowledge Centre (KCE); 2008. https://kce.fgov.be/sites/default/files/page_documents/ d20081027315.pdf.

37. Dixon-Woods M, McNicol S, Martin G. Ten challenges in improving quality in healthcare: lessons from the Health Foundation's programme evaluations and relevant literature. BMJ Qual Saf. 2012;21:876-84. doi:10.1136/bmjas2011-000760.

38. Fitzpatrick-Lewis D, Ganann R, Krishnaratne S, Ciliska D, Kouyoumdjian F, Hwang SW. Effectiveness of interventions to improve the health and housing status of homeless people: a rapid systematic review. BMC Public Health. 2011;11:638. doi:10.1186/1471-2458-11-638.

39. Foerster $\mathrm{V}$, Murtagh J, Fiander M. Pulsed dye laser therapy for port wine stains. Technology report number 78. Ottawa, ON: Canadian Agency for Drugs and Technologies in Health; 2007. http://www.cadth.ca/media/pdf/ 13008_tr_Port-Wine-Stains_e.pdf.

40. Geddes R, Frank J, Haw S. A rapid review of key strategies to improve the cognitive and social development of children in Scotland. Health Policy. 2011;101:20-8. doi:10.1016/j.healthpol.2010.08.013.

41. Hailey D. Health technology assessment. Singapore Med J. 2006;47:187-92. quiz 93.

42. Hailey D. A preliminary survey on the influence of rapid health technology assessments. Int J Technol Assess Health Care. 2009;25:415-8. doi:10.1017/ S0266462309990067.

43. Hailey D, Corabian P, Harstall C, Schneider W. The use and impact of rapid health technology assessments. Int J Technol Assess Health Care. 2000;16:651-6.

44. Hildon Z, Neuburger J, Allwood D, van der Meulen J, Black N. Clinicians' and patients' views of metrics of change derived from patient reported outcome measures (PROMs) for comparing providers' performance of surgery. BMC Health Serv Res. 2012;12:171. doi:10.1186/1472-6963-12-171.

45. Hulstaert F, Thiry N, Eyssen M, Vrijens F. Pharmaceutical and nonpharmaceutical interventions for Alzheimer's Disease, a rapid assessment. KCE reports 111C. Brussels: Health Technology Assessment (HTA) and Belgian Health Care Knowledge Centre (KCE); 2009. https://kce.fgov.be/sites/default/files/ page_documents/d20091027329.pdf.

46. Jahangirian M, Eldabi T, Garg L, Jun GT, Naseer A, Patel B, et al. A rapid review method for extremely large corpora of literature: Applications to the domains of modelling, simulation, and management. Int J Inf Manag. 2011;31:234-43. doi:10.1016/j.ijinfomgt.2010.07.004.

47. Jolliffe D, Farrington DP. A rapid evidence assessment of the impact of mentoring on re-offending: a summary. London: Home Office; 2007. http://www.crim.cam.ac.uk/people/academic_research/david_farrington/ olr1107.pdf.

48. Kelly BJ, Perkins DA, Fuller JD, Parker SM. Shared care in mental illness: A rapid review to inform implementation. Int J Ment Health Syst. 2011;5:31. doi:10.1186/1752-4458-5-31.

49. Konnyu KJ, Kwok E, Skidmore B, Moher D. The effectiveness and safety of emergency department short stay units: a rapid review. Open Med. 2012;6:e10-6.

50. Legrand M, Coudron V, Tailleu I, Rooryck N, Dupont K, Boudrez P, et al. Videoregistratie van endoscopische chirurgische interventies: rapid assessment. KCE reports 101A. Brussels: Health Technology Assessment (HTA) and Belgian Health Care Knowledge Centre (KCE); 2008. https:// kce.fgov.be/sites/default/files/page_documents/d20081027397.pdf.

51. Lewis $R$, Whiting $P$, ter Riet $G, O^{\prime}$ Meara $S$, Glanville J. A rapid and systematic review of the clinical effectiveness and cost-effectiveness of debriding agents in treating surgical wounds healing by secondary intention. Health Technol Assess. 2001;5:1-131.

52. Low N, Bender N, Nartey L, Redmond S, Shang A, Judith S. Revised rapid review of evidence for the effectiveness of screening for genital chlamydial infection in sexually active young women and men. London: The National Institute for Health and Care Excellence (NICE); 2006. https://www.nice.org.uk/guidance/ph3/evidence/review-2-reviewof-evidence-for-the-effectiveness-of-screening-for-genital-chlamydialinfection-in-sexually-active-young-women-and-men2.

53. Maddern G, Cooter R, Lee I. Rapid review: clinical treatments for wrist ganglia. ASERNIP-S report number 63. Adelaide: Australian Safety and Efficacy Register of New Interventional Procedures - Surgical (ASERNIP-S). http://www.surgeons.org/media/310861/Clinical_treatment_for_ wrist_ganglia.pdf.
54. Maddern G, Fitridge R, Woodruff P, Leopardi D, Hoggan B. Rapid review: treatments for varicose veins. ASERNIP-S report number 66. Adelaide: Australian Safety and Efficacy Register of New Interventional Procedures Surgical (ASERNIP-S). http://www.surgeons.org/media/300551/ Treatments_for_varicose_veins.pdf.

55. Maddern G, Fitridge R, Woodruff P, Leopardi D, Hoggan B. Rapid review: upper airway surgery for the treatment of adult obstructive sleep apnoea. ASERNIP-S report number 67. Adelaide: Australian Safety and Efficacy Register of New Interventional Procedures - Surgical (ASERNIP-S). https://www.surgeons.org/media/300727/Upper_airway_surgery_ for_adult_OSA.pdf.

56. Maddern G, Morrison G, Lathlean T. Rapid review: diagnostic arthroscopy for conditions of the knee. ASERNIP-S report number 64. Adelaide: Australian Safety and Efficacy Register of New Interventional Procedures - Surgical (ASERNIP-S). http://www.surgeons.org/media/311101/Diagnostic_ arthroscopy_for_conditions_of_the_knee.pdf.

57. Maddern G, Bridgewatern F, Perera C. Rapid review: male non-therapeutic circumcision. ASERNIP-S report number 65. Adelaide: Australian Safety and Efficacy Register of New Interventional Procedures - Surgical (ASERNIP-S); 2008. http://www.surgeons.org/media/292210/Male_nontherapeutic_circumcision.pdf.

58. Mann R, Gilbody S. Validity of two case finding questions to detect postnatal depression: a review of diagnostic test accuracy. J Affect Disord. 2011;133:388-97. doi:10.1016/j.jad.2010.11.015.

59. Marsh K, Fox C. The benefit and cost of prison in the UK. The results of a model of lifetime re-offending. J Exp Criminol. 2008;4:403-23. doi:10.1007/s11292-008-9063-3.

60. McGregor M, Brophy JM. End-user involvement in health technology assessment (HTA) development: a way to increase impact. Int J Technol Assess Health Care. 2005;21:263-7.

61. McMurran M. Individual-level interventions for alcohol-related violence: a rapid evidence assessment. Crim Behav Ment Health. 2012;22:14-28. doi:10.1002/cbm.821.

62. McRobbie H, Hajek P, Bullen C, Feigin V. Rapid review of non NHS treatments for smoking cessation. Smoking Cessation Programme. London: The National Institute for Health and Care Excellence (NICE); 2006. http://www.nice.org.uk/guidance/ph10/documents/evidencesummary-nonnhs-treatments2.

63. Middleton P, Simpson B, Maddern G. Spinal cord stimulation (neurostimulation): an accelerated systematic review. ASERNIP-S report number 43. Adelaide: Australian Safety and Efficacy Register of New Interventional Procedures Surgical (ASERNIP-S); 2003. http://www.surgeons.org/media/17785/ SCSaccelreview0603.pdf.

64. Mitchell MD, Williams $K$, Kuntz G, Umscheid CA. When the decision is what to decide: using evidence inventory reports to focus health technology assessments. Int J Technol Assess Health Care. 2011;27:127-32. doi:10.1017/ S0266462311000031.

65. Moran R, Davidson P. An uneven spread: a review of public involvement in the National Institute of Health Research's Health Technology Assessment program. Int J Technol Assess Health Care. 2011;27:343-7. doi:10.1017/ S0266462311000559.

66. Murphy G, Prichett-Pejic W, Severn M. Non-emergency telecardiology consultation services: rapid review of clinical and cost outcomes. Technology report number 134. Ottawa, ON: Canadian Agency for Drugs and Technologies in Health; 2010. http://www.cadth.ca/media/pdf/ H0501_Telecardiology_Report_e.pdf.

67. Nasser M. Evidence summary: is smoking cessation an effective and cost-effective service to be introduced in NHS dentistry? Br Dent J. 2011;210:169-77. doi:10.1038/sj.bdj.2011.117.

68. Ndegwa S, Prichett-Pejic W, McGill S, Murphy G, Prichett-Pejic W, Severn M. Teledermatology services: rapid review of diagnostic, clinical management, and economic outcomes. Technology report number 135. Ottawa, ON: Canadian Agency for Drugs and Technologies in Health; 2010. http:// www.cadth.ca/media/pdf/H0502_Teledermatology_Report_e.pdf.

69. O'Meara S, Riemsma R, Shirran L, Mather L. G. ter Riet G. A rapid and systematic review of the clinical effectiveness and cost-effectiveness of orlistat in the management of obesity. Health Technol Assess. 2001;5:1-81.

70. Obyn C, Mambourg F. Rapid assessment van enkele nieuwe behandelingen voor prostaatkanker en goedaardige prostaathypertrofie: High-Intensity Focused Ultrasound (HIFU) voor prostaatkanker. Photoselective 
Vaporization of the Prostate (PVP) en holmium laser voor goedaardige prostaathypertrofie. KCE reports 89A. Brussels: Belgian Health Care Knowledge Centre (KCE); 2008. https://kce.fgov.be/sites/default/files/ page_documents/d20081027361.pdf.

71. Saborido CM, Hockenhull J, Bagust A, Boland A, Dickson R, Todd D. Systematic review and cost-effectiveness evaluation of 'pill-in-the-pocket' strategy for paroxysmal atrial fibrillation compared to episodic in-hospital treatment or continuous antiarrhythmic drug therapy. Health Technol Assess. 2010;14:iii-iv. doi:10.3310/hta14310. 1-75.

72. Schnell-Inderst P, Hunger T, Hintringer K, Schwarzer R, Seifert-Klauss VR, Gothe $\mathrm{H}$, et al. Individual health services. GMS Health Technol Assess. 2011;7:Doc05. doi:10.3205/hta000096.

73. Singh D. Transforming chronic care. Evidence about improving care for people with long-term conditions. Birmingham: University of Birmingham Health Services Management Centre; 2005. http://www.download.bham. ac.uk/hsmc/pdf/transforming_chronic_care.pdf.

74. Singh D. Making the shift: key success factors. A rapid review of best practice in shifting hospital care into the community. Birmingham: University of Birmingham Health Services Management Centre; 2006. http://www.birmingham.ac.uk/Documents/college-social-sciences/socialpolicy/HSMC/publications/2006/Making-the-Shift-Key-Success-Factors.pdf.

75. Singh D. Improving care for people with long-term conditions: A review of UK and international frameworks. Birmingham: University of Birmingham Health Services Management Centre; 2006. http://www. improvingchroniccare.org/downloads/review_of_international_ frameworks_chris_hamm.pdf.

76. Smith J, Cheater F, Bekker H. Parents' experiences of living with a child with a long-term condition: a rapid structured review of the literature. Health Expect. 2013. doi:10.1111/hex.12040.

77. Stordeur S, Gerkens S, Roberfroid D. Interspinous implants and pedicle screws for dynamic stabilization of lumbar spine: rapid assessment. KCE reports 116C. Brussels: Health Technology Assessment (HTA) and Belgian Health Care Knowledge Centre (KCE); 2009. https://kce.fgov.be/sites/default/ files/page documents/d20091027346.pdf.

78. Sutton A, Grant MJ. Cost-effective ways of delivering enquiry services: a rapid review. Health Info Libr J. 2011;28:249-55. doi:10.1111/j.1471-1842.2011.00965.x.

79. Thigpen S, Puddy RW, Singer HH, Hall DM. Moving knowledge into action: developing the rapid synthesis and translation process within the interactive systems framework. Am J Community Psychol. 2012;50:285-94. doi:10.1007/s10464-012-9537-3.

80. Thomas J, Newman M, Oliver S. Rapid evidence assessments of research to inform social policy: taking stock and moving forward. Evid Policy. 2013;9:5-27. doi:10.1332/174426413X662572.

81. Tsakonas E, Moulton K, Spry C. FDG-PET to assess infections: a review of the evidence. Ottawa, ON: Canadian Agency for Drugs and Technologies in Health; 2008. http://www.cadth.ca/media/pdf/I3016_FDG-PET_Assess_ Infections_htis-3_e.pdf.

82. Van Brabandt $\mathrm{H}$, Neyt M. Endobronchial valves in the treatment of severe pulmonary emphysema: a rapid Health Technology Assessment. KCE reports 114C. Brussels: Health Technology Assessment (HTA) and Belgian Health Care Knowledge Centre (KCE); 2009. https://kce.fgov.be/sites/default/files/ page_documents/d20091027339.pdf.

83. Vlayen J, Camberlin C, Paulus D, Ramaekers D. Rapid assessment van nieuwe wervelzuil technologieën: totale discusprothese en vertebro/ballon kyfoplastie. KCE reports 39A. Brussels: Belgian Health Care Knowledge Centre (KCE); 2006. https://kce.fgov.be/sites/default/files/page_documents/ d20061027338.pdf.

84. York A, Crawford C, Walter A, Walter JAG, Jonas WB, Coeytaux R. Acupuncture research in military and veteran populations: a rapid evidence assessment of the literature. Med Acupuncture. 2011;23:229-36. doi:10.1089/acu.2011.0843.

85. Zechmeister I, Schumacher I. The impact of health technology assessment reports on decision making in Austria. Int J Technol Assess Health Care. 2012;28:77-84. doi:10.1017/\$0266462311000729.

86. Sturm L, Cameron AL. Brief review: Fast-track surgery and enhanced recovery after surgery (ERAS) programs. Adelaide: Australian Safety and Efficacy Register of New Interventional Procedures - Surgical (ASERNIP-S); 2009 http:/www.surgeons.org/media/299206/RPT_2009-12-09_Enhanced_Patient_ Recovery_Programs.pdf.

87. Birmingham and Black Country Strategic Health Authority. Reducing unplanned hospital admissions. What does the literature tell us?
Birmingham: Birmingham and Black Country Strategic Health Authority; 2008. http:/www.birmingham.ac.uk/Documents/college-social-sciences/ social-policy/HSMC/publications/2006/Reducing-unplanned-hospitaladmissions.pdf.

88. Brunton G, Paraskeva N, Caird J, Bird KS, Kavanagh J, Kwan I, et al. Psychosocial predictors, assessment and outcomes of cosmetic interventions. A systematic rapid evidence review. London: EPPI-Centre Social Science Research Unit, Institute of Education, University of London; 2013. http://eppi.ioe.ac.uk/cms/LinkClick.aspx?fileticket=Ge_ RehINz8Q\%3D.

89. Caird J, Hinds K, Kwan I, Thomas J. A systematic rapid evidence assessment of late diagnosis. London: EPPI-Centre, Social Science Research Unit, Institute of Education, University of London; 2012. http://eppi.ioe.ac.uk/cms/ LinkClick.aspx?fileticket=qbwCNWu8qHw\%3D.

90. Carr SC, Leggatt-Cook C, Clarke M, MacLachlan M, Papola TS, Pais J, et al. What is the evidence of the impact of increasing salaries on improving the performance of public servants, including teachers, doctors/nurses, and mid-level occupations, in low- and middle-income countries: Is it time to give pay a chance? London: EPPI-Centre Social Science Research Unit, Institute of Education, University of London; 2011. http://eppi.ioe.ac.uk/cms/ LinkClick.aspx?fileticket=bFX9uXkOyal\%3d\&tabid=3208\&mid=5983.

91. Doran C. The costs and benefits of interventions in the area of mental health: a rapid review. An Evidence Check review brokered by the Sax Institute for the Mental Health Commission of NSW. Sax Institute: Haymarket; 2013. https://www.saxinstitute.org.au/wp-content/uploads/ MH-costs-and-benefits-of-intervention_FINAL2.pdf.

92. Phillipson L, Larsen-Truong K, Jones S, Pitts L. Improving cancer outcomes among culturally and linguistically diverse communities: a rapid review. An Evidence Check review brokered by the Sax Institute for the Cancer Institute NSW. Sax Institute: Haymarket; 2012. https://www.saxinstitute.org.au/wpcontent/uploads/Improving-cancer-outcomes-among-CALD-communities230413v2.pdf.

93. Rissel C, Curac N, Greenaway M, Bauman A. Key health benefits associated with public transport: a rapid review: An Evidence Check review brokered by the Sax Institute for the NSW Ministry of Health. Sax Institute: Haymarket; 2012. https://www.saxinstitute.org.au/wp-content/uploads/05_Key-healthbenefits-associated-with-public-transport.pdf.

94. Tripney J, Bird KS, Kwan I, Kavanagh J. The impact of post-abortion care family planning counselling and services in low-income countries: a systematic review of the evidence. London: EPPI-Centre, Social Science Research Unit, Institute of Education, University of London; 2011. http:// eppi.ioe.ac.uk/cms/LinkClick.aspx?fileticket=X_JbXQTVDEQ\%3D\&tabid= $3062 \& \mathrm{mid}=5694$.

95. Casadesus D. Surgical resection of rectal adenoma: a rapid review. World J Gastroenterol. 2009;15:3851-4.

96. London Health Commission. Health inequalities and equality impact assessment of 'Healthcare for London: consulting the capital'. Scientific Annex 2: rapid evidence review and appraisal. London: London Health Commission: 2008 .

97. Curson JA, Dell ME, Wilson RA, Bosworth DL, Baldauf B. Who does workforce planning well? Workforce review team rapid review summary. Int J Health Care Qual Assur. 2010;23:110-9. doi:10.1108/09526861011010712.

98. De Alwis KLNSK, Dunt D, Bennett N, Bull A. Increasing vaccination among healthcare workers - Review of strategies and a study of selected Victorian hospitals. Healthcare Infection. 2010;15:63-9.

99. Government Social Research Unit. The Magenta Book: guidance notes for policy evaluation and analysis. Background paper 2: what do we already know? Harnessing existing research. London: Government Social Research Unit; 2007. http://resources.civilservice.gov.uk/wp-content/uploads/2011/09/ the complete magenta_book_2007 edition2.pdf.

100. Ontario Ministry of Health and Long-Term Care. Endovascular repair of abdominal aortic aneurysms in low surgical risk patients: rapid review. Toronto, ON: Medical Advisory Secretariat; 2010.

101. Moyad M, Vitamin D. A rapid review. Urol Nurs. 2008;28:5.

102. Moyad M. Heart health = urologic health and heart unhealthy =urologic unhealthy: rapid review of lifestyle changes and dietary supplements. Urol Clin North Am. 2011;38:359-67.

103. Parker H. Making the shift: a review of NHS experience. Birmingham: University of Birmingham Health Services Management Centre; 2006. http://www.birmingham.ac.uk/Documents/college-social-sciences/socialpolicy/HSMC/research/making-the-shift.pdf. 
104. Thavaneswaran P. Rapid review: robotic-assisted surgery for urological, cardiac and gynaecological procedures ASERNIP-S report number 75 . Adelaide: Australian Safety and Efficacy Register of New Interventional Procedures - Surgical (ASERNIP-S); 2009. http://www.surgeons.org/media/ 299238/RPT_2009-12-09_Robotic-assisted_Surgery.pdf.

105. Tonmukayakul U, Velasco RP, Tantivess S, Teerawattananon Y. Lessons drawn from research utilization in the maternal iodine supplementation policy development in Thailand. BMC Public Health. 2012;12:391. doi:10.1186/1471-2458-12-391.

106. Van de Velde S, De Buck E, Dieltjens T, Aertgeerts B. Medicinal use of potato-derived products: conclusions of a rapid versus full systematic review. Phytother Res. 2011;25:787-8. doi:10.1002/ptr.3356.

107. Van Brabandt $H$, Neyt M. Percutaneous heart valve implantation in congenital and degenerative valve disease: a rapid Health Technology Assessment. KCE reports 95. Brussels: Health Technology Assessment (HTA) and Belgian Health Care Knowledge Centre (KCE); 2008. https://kce.fgov.be/ sites/default/files/page_documents/d20081027381.pdf.

108. van Swieten JC, Heutink P. Mutations in progranulin (GRN) within the spectrum of clinical and pathological phenotypes of frontotemporal dementia. Lancet Neurol. 2008;7:965-74. doi:10.1016/S1474-4422(08)70194-7.

109. World Health Organization (WHO). WHO rapid advice guidelines on pharmacological management of humans infected with avian influenza A (H5N1) virus. Geneva: WHO; 2006. http://www.who.int/medicines/ publications/WHO_PSM_PAR_2006.6.pdf?ua=1.

110. Batten J. Letter to the Editor: Comment on editorial literature reviews as a research strategy. J Sch Nurs. 2012;28:409.

111. Watt A, Cameron A, Sturm L, Lathlean T, Babidge W, Blamey S, et al. Rapid versus full systematic reviews: validity in clinical practice? ANZ J Surg. 2008;78:1037-40. doi:10.1111/j.1445-2197.2008.04730.x.

112. London Health Commission. Health inequalities and equality impact assessment of 'Healthcare for London: consulting the capital'. Scientific annex II rapid evidence review and appraisal. Birmingham: West Midlands Public Health Observatory; 2008. http://www.apho.org.uk/resource/ item.aspx?RID=52757.

113. Civil Service. What is a rapid evidence assessment? London: Civil Service; 2011. http://www.civilservice.gov.uk/networks/gsr/resources-and-guidance/ rapid-evidence-assessment/what-is.

114. Ehlers L, Vestergaard M, Kidholm K, Bonnevie B, Pedersen PH, Jørgensen T, et al. Doing mini-health technology assessments in hospitals: A new concept of decision support in health care? Int J Technol Assess Health Care. 2006;22:295-301. doi:10.1017/S0266462306051178.

115. Grant MJ, Booth A. A typology of reviews: an analysis of 14 review types and associated methodologies. Health Information Libraries J. 2009;26:91-108. doi:10.1111/j.1471-1842.2009.00848.x.

116. Canadian Agency for Drugs and Technologies in Health (CADTH). Rapid review summit: then, now and in the future. 3-4 February 2015. CADTH Summit Series. CADTH: Vancouver, BC; 2015. http://www.cadth.ca/cadthsummit-series

117. Moher DSK, Simera I, Altman DG. Guidance for developers of health research reporting guidelines. PLoS Med. 2010;7, e1000217.

118. Tricco AC, Zarin W, Antony J, Hutton B, Moher D, Sherifali D, et al. An international survey and modified Delphi approach revealed numerous rapid review methods. J Clin Epidemiol. 2015; pll-S0895-4256(15):00388-1.

119. Hartling L, Guise JM, Kato E, Anderson J, Aronson N, Belinson S, et al. EPC methods: an exploration of methods and context for the production of rapid reviews. Rockville MD: Agency for Healthcare Research and Quality (US); 2015.

120. Featherstone RM, Dryden DM, Foisy M, Guise JM, Mitchell MD, Paynter RA et al. Advancing knowledge of rapid reviews: an analysis of results, conclusions and recommendations from published review articles examining rapid reviews. Syst Rev. 2015;4:50. doi:10.1186/s13643-015-0040-4.

\section{Submit your next manuscript to BioMed Central and take full advantage of:}

- Convenient online submission

- Thorough peer review

- No space constraints or color figure charges

- Immediate publication on acceptance

- Inclusion in PubMed, CAS, Scopus and Google Scholar

- Research which is freely available for redistribution

Submit your manuscript at www.biomedcentral.com/submit 